\title{
Assessment of health care services for people with stoma: a multi- case study
}

\author{
Avaliação dos serviços de atenção à saúde das pessoas com estomias: estudo de casos \\ múltiplos
}

Ravena Rieelly Araújo Moura ${ }^{1}$, Juliano Teixeira Moraes ${ }^{1}$, Eliete Albano de Azevedo Guimarães ${ }^{1}$

\begin{abstract}
Objective: to evaluate the health care services of people with stoma. Methods: a multi-case study that analyzed the implementation of five regional services. Three components were defined, namely Service management, Clinical care and Educational assistance. The degree of implementation set by a score system was classified as complete, satisfactory, poor, not implemented. Results: a service was evaluated with "completely implemented" and another as "not implemented". The best components evaluated were Clinical Care and Service Management; the one that obtained lower assessment was Educational assistance. Structural limitations included a lack of complete health staff and lack of clinical and organizational protocols. In the Process, there was a shortage of consultations carried out by the team, formation of support groups and health education. Conclusion: the regional services surveyed are not adequate to subsidize planning, monitoring and services to people with stoma, as they present structural and procedural problems that interfere with the quality of care.
\end{abstract}

Descriptors: Ostomy; Health Care (Public Health); Health Services; Program Evaluation.

Objetivo: avaliar os serviços de atenção à saúde das pessoas com estomias. Métodos: estudo de casos múltiplos que analisou a implantação de cinco serviços regionais. Foram definidos três componentes: Gerenciamento dos serviços, Assistência clínica e Assistência educacional. Grau de implantação definido por sistema de escores classificado como plena, satisfatória, incipiente, não implantado. Resultados: um serviço foi avaliado com "implantação plena" e outro como "não implantado". Os melhores componentes avaliados foram Assistência clínica e Gerenciamento dos serviços; o que obteve menor avaliação foi Assistência educacional. As limitações estruturais compreenderam carência da equipe de saúde completa e ausência de protocolos clínicos e organizacionais. No Processo, identificou-se escassez de consultas realizadas pela equipe, formação de grupos de apoio e educação em saúde. Conclusão: os serviços regionais pesquisados não estão adequados para subsidiar o planejamento, monitoramento e serviços às pessoas com estomias, pois apresentam problemas estruturais e processuais que interferem na qualidade do cuidado.

Descritores: Estomia; Atenção à Saúde; Serviços de Saúde; Avaliação de Programas e Projetos de Saúde.

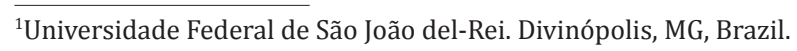




\section{Introduction}

The organization of health care to people with stoma in Brazil has been restructured from a model of care network, regionalized and hierarchical, in order to guarantee a comprehensive care to people with disabilities ${ }^{(1)}$. This new model is based on interdisciplinary, preventive, individualized and systematized care, aiming at early rehabilitation and improvement of the quality of life of people with stoma ${ }^{(1-2)}$.

The provision of Health Care Services for People with Stomata was incorporated into the Policy of Care to People with Disabilities, which aimed to offer organized care in Health Care Networks, promote actions related to Primary Health Care, establish reference and counter-reference flows and mechanisms, ensure monitoring/evaluation of activities and promote continuing education of professionals ${ }^{(1)}$.

Therefore, it is hoped to reach the organization of services within the health territories, the qualified attention to the individual and his/her family, the stimulation of self-care, besides the prescription and the provision of suitable collecting equipment and auxiliary protection and safety mechanisms ${ }^{(2)}$. The decentralization of these services subsidizes the planning and monitoring of care $^{(3)}$. However, little is known about the conditions of accredited services and the effects of this intervention on the quality of care for people with stoma.

In addition, there are still few studies on the analysis of the implementation of the Care Services for People with Stoma in Brazil, and the evaluation is not yet an institutionalized practice, being influenced by the lack of tradition and understanding of the professionals' need for evaluation of the daily routine in which they are inserted ${ }^{(4)}$. In this context, this study aimed to evaluate the health care services targeted at people with stoma.

\section{Methods}

This is a multiple case study focused on the contextual analysis of program implementation that consists of studying the relationships between an intervention and its context during its implementation. Case studies are conducive to the analysis of the implementation of programs or policies, in which the explanations of the facts are derived from the depth of the case analysis, not from the number of units. Each case consists of a complete study, in which convergent or divergent evidence is sought in relation to the facts and conclusions for the case $\mathrm{e}^{(5-6)}$.

This research limited its scope of research in the dimensions of structure (resources, employees and their organization) and process (services or goods produced $)^{(5)}$, which integrate the components evaluated in the Health Care Service for People with Stomata: Management of services, Clinical assistance and Educational assistance.

Five type I services implemented in the regional headquarters of the western region of Minas Gerais were analyzed in 2016, which is composed of 54 cities, grouped in six health micro-regions, with an estimated population of 1,194,156 inhabitants. Currently, the region has six services, of which five are type I and one type II. The Type II Care Service was excluded from this study because it presented organizational context and purposes different from those classified as type I, requiring, therefore, a new evaluation plan.

In the first moment, documents, normative acts and scientific texts were analyzed. Also, five working meetings were held with three researchers, a technical representative reference in the stomata of the State Health Department of Minas Gerais, Brazil, and two specialists in the area. The components of the logical model, the evaluative questions and the criteria to be used in the matrix of measures and analysis used in 
this evaluation were defined in a consensual way. For each of the evaluation questions, the parameters, the types of approaches, the data sources and the collection techniques were defined.

Then, two visits were made to these services in April 2016. The first one consisted of a meeting with managers and nurses responsible for the services, previously contacted by telephone, to present the evaluation proposal, the authorization terms and the informed consent form. At that time, the services were also presented to the researchers. During the second visit, we performed the data collection by using an adapted semi-structured instrument ${ }^{(7)}$. In addition to the interviews, medical records, documents and data from the information system on pharmaceutical care management were analyzed. During these visits, interviews were conducted with the health professionals working in the service. The data were tabulated and analyzed with the softwares Epidata, version 3.1, and Statistical Package for the Social Sciences, version 19.0 .

To estimate the degree of implantation of the Health Care Services of People with Type I Stomata, a matrix of analysis was developed. The degree of implementation was defined through a system of scores, with weights differentiated for each criterion, according to the level of importance assigned. In order to construct the scores, the observed values ( $\Sigma$ of the scores of the indicators) were determined and the degree of implementation in percentage (observed $\Sigma / \Sigma$ of maximum possible scores $\mathrm{x} 100$ ) was calculated for each component, and later we performed the sum of the components for the calculation of the degree of total implementation ${ }^{(7)}$.

The total of the maximum score established was 175 points. The maximum score of 25 points was set for the Structure dimension and 25 points for the Process dimension, in the Service management component; 36 points for Structure and 39 points for Process, in the Clinical Care component; and 23 points for Structure and 27 points for Process, in the Educational Assistance component. Each component totaled 50,
75 and 50 points respectively, after the sum of the criteria of the dimensions of structure and process.

From the degree of implementation of each component, the categories for the classification of the Health Care Services of People with Type I Stomata were defined, adopting the scores ${ }^{(2)}$ : complete $(80.0 \%|--| 100.0 \%)$; satisfactory $(60.0 \%|--| 79.9 \%)$; poor $(40.0 \%|--| 59.9 \%)$; and not implemented $(<40.0 \%)$.

In order to verify the relationship between the total score obtained in the questionnaire of these services and the components of Structure and Process of Management, Clinical and Educational Assistance, we used the Pearson correlation. For the analyzes, the significance level of $5 \%$ was adopted. Correlation is classified as weak when values between 0 and 0.3 are obtained; moderate, values between 0.3 and 0.5 ; and strong, when values are above 0.5 .

This study was approved by the Ethics Committee of Research with Human Beings of the Federal University of São João del-Rei, according to Opinion No. $1,251,725$.

\section{Results}

The elaborated model allowed evaluating the Health Care Services of People with Type I Stomata. The results showed that the degree of implementation of the services ranged from a complete to an poor implantation. One service reached a complete implementation (97.1\%), meeting most of the evaluated items. Three of them had a satisfactory performance $(60.5 \%, 61.1 \%$ and $73.7 \%)$ and one was classified as not implemented (36.0\%).

The components with the best performances were Clinical Care and Service Management. It should be noted that Educational Assistance was the component that obtained the lowest score, with problems both in structural and procedural issues.

In the structure dimension, problems were identified regarding physical facilities, equipment and human resources. The results pointed out nur- 
sing professionals working in services, but also lack of physicians and social workers in the daily work. Most of the services did not have clinical and organizational protocols; the physical facilities were not suitable for carrying out the activities, especially in regard to clinical care; and the information system on pharmaceutical care management was inoperative, implying reports of the activities performed (Table 1).

In the Process dimension, deficiencies were highlighted in the elaboration of reference and counter-reference flows in the health care network; in the use of the information system on pharmaceutical care management; lack of availability of consultations with physicians and social workers; in the detection of complications, with referral to the Health Care Service of People with Type II Stomata at the moment of the consultation; and in the absence of group educational activities. The Educational Assistance component obtained a lower evaluation, with highlight to the insufficiency in the accomplishment of health education activities for people with stomata; guidelines on family and social life; counseling to Primary Health Care professionals for adequate attention to people with stomata and their respective relatives (Table 1).

Figure 1 shows the convergent and divergent elements of the Structure and Process dimensions, evidenced in the evaluated Health Care Services for People with Stomata.

Table 1 - Degrees of Implementation of Health Care Services for People with Type I Stomata according to the dimensions Structure and Process and the components Service Management, Clinical Care and Educational Assistance

\begin{tabular}{|c|c|c|c|c|c|}
\hline \multirow[t]{2}{*}{ Dimensions/components } & \multicolumn{5}{|c|}{$\begin{array}{l}\text { Degrees of implementation of type I } \\
\text { health services }\end{array}$} \\
\hline & 1 & 2 & 3 & 4 & 5 \\
\hline \multicolumn{6}{|l|}{ Structure } \\
\hline \multicolumn{6}{|l|}{ Service management } \\
\hline Physical facilities & - & 100.0 & 100.0 & - & 100.0 \\
\hline Equipment & 62.5 & 100.0 & 100.0 & - & 100.0 \\
\hline Human Resources & 33.3 & 66.6 & 33.3 & 33.3 & 100.0 \\
\hline Organizational protocols & 100.0 & - & - & - & 100.0 \\
\hline \multicolumn{6}{|l|}{ Clinical care } \\
\hline Physical facilities & - & - & 100.0 & - & - \\
\hline Equipment & 28.5 & 76.1 & 85.7 & - & 90.4 \\
\hline Human Resources & 33.3 & 33.3 & 33.3 & 33.3 & 100.0 \\
\hline Clinical Protocols & - & 100.0 & - & - & 100.0 \\
\hline \multicolumn{6}{|l|}{ Educational assistance } \\
\hline Physical facilities & 100.0 & 100.0 & 100.0 & - & 100.0 \\
\hline Human Resources & 25.0 & 75.0 & 25.0 & 25.0 & 100.0 \\
\hline Reports of activities carried out & - & 100.0 & - & - & 100.0 \\
\hline \multicolumn{6}{|l|}{ Process } \\
\hline \multicolumn{6}{|l|}{ Service management } \\
\hline Performance/updating of enrollment of people with stoma & 100.0 & 100.0 & 100.0 & 100.0 & 100.0 \\
\hline Acquisition of collecting and auxiliary protection and safety equipment & 100.0 & 100.0 & 100.0 & 100.0 & 100.0 \\
\hline Distribution of collecting and auxiliary protection and safety equipment & 100.0 & 100.0 & 100.0 & 100.0 & 100.0 \\
\hline Elaboration of reference and counter-reference flows in the Health Care Network & - & - & 100.0 & - & 100.0 \\
\hline Use of the information system on pharmaceutical care management & - & 100.0 & - & - & 100.0 \\
\hline \multicolumn{6}{|l|}{ Clinical care } \\
\hline Consultation with physician and social worker & - & 100.0 & - & - & 100.0 \\
\hline Consultation with the nurse & 100.0 & 100.0 & 100.0 & 100.0 & 100.0 \\
\hline Guidance on self-care and prevention of complications at the time of consultation & 100.0 & 100.0 & 100.0 & 100.0 & 100.0 \\
\hline Detection of complications with referral at the time of consultation & 100.0 & - & 100.0 & - & 100.0 \\
\hline \multicolumn{6}{|l|}{ Educational assistance } \\
\hline Realization of group meetings & - & 100.0 & - & - & 100.0 \\
\hline Carrying out health education activities for people with stoma & - & 100.0 & - & - & 100.0 \\
\hline $\begin{array}{l}\text { Guidelines for Primary Health Care professionals for adequate attention to people and their } \\
\text { family members }\end{array}$ & - & - & - & - & 100.0 \\
\hline
\end{tabular}




\begin{tabular}{|c|c|c|}
\hline Dimension & Convergent elements & Divergent elements \\
\hline Structure & $\begin{array}{l}\text { Room for distribution and storage of collecting and } \\
\text { auxiliary protection and safety equipment; } \\
\text { Meeting room; } \\
\text { Table with chairs, cabinets, filing cabinets, stretcher } \\
\text { lined with waterproof material; two-step ladder, } \\
\text { anthropometric scale, stethoscope, hand hygiene sink; } \\
\text { phone, computer, internet; } \\
\text { Access to information networks and computer equipment; } \\
\text { Presence of nurses in services. }\end{array}$ & $\begin{array}{l}\text { Shortage of clinical and organizational protocols; } \\
\text { Failure to use the information system on pharmaceutical care } \\
\text { management; } \\
\text { Absence of toilet with hygienic showers; } \\
\text { Absence of sphygmomanometer and pediatric scale; } \\
\text { Absence of mirror with minimum dimensions of } 120 \times 50 \mathrm{~cm} \text {; } \\
\text { Lack of professionals: social worker and physician. }\end{array}$ \\
\hline Process & $\begin{array}{l}\text { Realization of registrations; } \\
\text { Update of registrations; } \\
\text { Acquisition and control of collecting and auxiliary } \\
\text { protection and safety equipment; } \\
\text { Verification of the storage conditions of collecting and } \\
\text { auxiliary protection and safety equipment; } \\
\text { Supply of devices and collectors to the person with the } \\
\text { stoma; } \\
\text { Individual consultations. }\end{array}$ & $\begin{array}{l}\text { Insufficiency of consultation with physician and social worker; } \\
\text { Lack of elaboration of reference and counter-reference flows } \\
\text { in the Health Care Network, as well as guidelines for primary } \\
\text { health care professionals to adequately provide care to the } \\
\text { person with the stoma and their family members; } \\
\text { Lack of health education activities; deficits in group visits and } \\
\text { guidelines on in family and social life; } \\
\text { Shortage of support groups; } \\
\text { Underutilization of the information system on pharmaceutical } \\
\text { care management. }\end{array}$ \\
\hline
\end{tabular}

Figure 1 - Convergent and divergent elements of the Structure and Process dimensions in the Health Care Services for People with Type I Stomata

To identify the components that most contributed to the total degree of implementation of the services, the Pearson correlation was performed. We identified that, for all items of the evaluated components, the correlation was strong. The Process dimension of the Service Management component obtained the lowest correlation value, being the item that least contributed to the total score of the degree of implementation $(\mathrm{R}=0.966)$. With the exception of the process dimension in Service Management, all other items obtained significant correlation.

\section{Discussion}

The issue on the external validity of the case study, a propitious method used to analyze the implementation of the Health Care Services of People with Type I Stomata, can be placed as a limitation if one considers the number of observations made. Add to this the approach used to analyze the degree of implementation of the services (quantitative), which, although having answered the evaluation questions, does not qualify the variables in the context that can explain the findings, for being very normative.
With the obtained results, we can list some of the contributions of the present study, such as the knowledge of the critical points that prevent the services from performing their activities with quality in the care of people with stoma, as well as the proposition of possible solutions to the identified problems.

Although the services are in operation, we observed the non-fulfillment of some purposes established in the guidelines for health care of people with stoma ${ }^{(1)}$, namely the organization and promotion of actions related to primary health care, the establishment of reference and counter-reference flows and mechanisms, and the promotion of permanent education of professionals for providing adequate care to the person with stoma and their family members. Thus, there has been the maintenance of an organization centered on the traditional model, based on the distribution and storage of devices to the detriment of comprehensive care, characterized by interdisciplinary care, focused on the individual and the family, aimed at early rehabilitation and improvement of the quality of life ${ }^{(1-2)}$.

Deficiencies in the structure of the Care Ser- 
vices to People with Stomata were also observed in a study carried out in Minas Gerais, Brazil ${ }^{(2)}$, which identified that both structure and process were not in accordance with that recommended in the established legal guidelines ${ }^{(1)}$. The regional services must be restructured in accordance with the norms established and agreed by the State Health Department ${ }^{(1)}$, which establish adequate physical structures and an interdisciplinary team capable of carrying out actions aimed at self-care, prevention of complications in the stomata and rehabilitation of patients with stoma.

However, this study evidenced an insufficiency of physicians and social workers in the composition of the interdisciplinary teams of the services, being the care performed by nurses in most of these places. It should be noted that the physician and the social worker have defined roles in the Health Care Services for People with Type I Stomata that include actions related to the stoma and peristaltic skin care, the prevention of complications, the evaluation of the biopsychosocial needs of the individual and their family, and guidance for self-care ${ }^{(1)}$. The absence of these professionals in the team overwhelms the nurse, resulting in a wide and diversified demand for administrative and clinical activities to the detriment of educational actions.

The results of this study showed that the interdisciplinary care expected by the policy of care to the person with stoma is disjointed and insufficient for the accomplishment of health education activities, provision of guidelines on social and family life, and realization of support groups. Professionals, specifically nurses, are still limited to activities with preferences for individualized actions that demand health care, to the detriment of group activities and service management.

It is important to highlight the underutilization of the information system for the management of pharmaceutical care, identified as an irregularity, which may be related to the inadequacy of computer equipment in the services and to the system's operational capacity, thus causing that professionals lose the ability to plan, organize and control the collecting and auxiliary protection equipment. In this perspective, in spite of the development of information and technologies, there is a mismatch between the advances related to the information and the dimension of the effectiveness of the products as intervention power over the management of the services ${ }^{(8)}$.

Another problem found in the management of the Health Care Services for People with Type I Stomata was the lack of establishment of reference and counter-reference flows and mechanisms in the health care network. This limitation greatly influences the comprehensive care to the person with stoma, who ends up losing the guarantee of access to the services they need. The establishment of a care line that involves Primary Medium and High Complexity Health Care implies continuity and integrality of care, from the preoperative phase to the rehabilitation of people with stoma ${ }^{(1)}$.

Therefore, in addition to the implementation of the Health Care Services for People with Stomata, it is necessary to train the professionals of the health care networks regarding the guidelines of the Health Care Policy for the Stomatized Person, so that they are prepared and aware to provide suitable assistance for the person with stoma. One of the main challenges faced by the professionals of these services to implement the health care policy for people with stoma refers to the acquisition of essential clinical skills, so that assistance can be provided with a view to the integrality of care in the health care networks ${ }^{(2)}$. Education, therefore, becomes a necessary tool for the performance of care services to stomatized people.

However, education-related activities were not guaranteed by most of the services, thus losing the opportunity to create links, establish reference and counter-reference flows and mechanisms, and ensure continuity of care, except in the service with complete implementation, in which the nurse specialized in stomatherapy became a prominent professional in the organization of the service.

Although it is important to have specialized 
nurses in stomatology in the services, there is no legal requirement for nurses who care for people with stoma to have this training. However, this professional has knowledge, specific training and skills for care, acting with mastery in preventive, therapeutic and rehabilitation actions ${ }^{(9)}$.

In this evaluation, we highlight that there is weak and poorly resolute educational assistance. Educational practices aimed at the qualification of work processes are often relegated to the background in the planning and organization of services ${ }^{(10)}$.

Education, in this way, becomes a necessary tool that guarantees the participatory inclusion of the person with the stoma in the society, in the development of skills to face new adaptations in face of physical, psychological and social transformations ${ }^{(11-12)}$. However, it was possible to identify that the guidelines on self-care, prevention of complications, exchange and handling of the ostomy bag, food and sexuality only happen during the individual consultation. The shortage of support groups for individuals and families has become a practice of inoperative health promotion and reinforces, in the evaluated services, the hegemonic model focused on professionals and curativist actions.

The support group is one of the strategies that favors the social reintegration of the person with sto$\mathrm{ma}$, since it focuses on independence for self-care and the restoration of autonomy in everyday life. This experience could add knowledge, skills and possibly reduce doubts, fears and insecurities of the person with the stoma, thus encouraging a better acceptance to the new lifestyle ${ }^{(13-15)}$.

\section{Conclusion}

Inadequate physical facilities, lack of complete health staff, lack of clinical and organizational protocols, lack of consultations, lack of support groups and health education, absence of clear definition of refe- rence counter-reference flows were some of the identified problems. The regional services researched in the present study are not adequate to subsidize planning, monitoring and services to people with stoma, as they present structural and procedural problems that interfere with the quality of care.

\section{Acknowledgements}

The Pró-Reitoria de Extensão of the Universidade Federal de São João del-Rei through the Programa de atenção à saúde da pessoa estomizada, process noㅡ 013/2015.

\section{Collaborations}

Moura RRA, Moraes JT and Guimarães EAA contributed to the conception and design, analysis and interpretation of the data, essay writing and critical review of the intellectual content and approval of the final version to be published.

\section{References}

1. Secretaria de Estado da Saúde de Minas Gerais. Linha de cuidados da pessoa estomizada. Secretaria de Estado de Saúde de Minas Gerais [Internet]. 2015 [citado 2018 mar 13]. Disponível em:http://www.saude.mg.gov.br/images / noticias_e_eventos/000_2016/2-abr-mai-jun/ ostomizados /24-06-Linha-de-Cuidados-daPessoa-Estomizada.pdf

2. Moraes JT, Amaral CFS, Borges EL, Ribeiro MS, Guimarães EAA. Evaluation of implantation of ostomy patient health care program. Rev Min Enferm. 2017; 21:e1017. doi: http://www.dx.doi. org/10.5935/1415-2762.20170027

3. Diebold L. Stoma and shame: engaging affect in the adaptation to a medical device. Aust J Adv Nurs [Internet]. 2016 [cited 2018 July 13]; 34(1):32-41. Available from: http://www.ajan.com.au/Vol34/ Issue1/4Diebold.pdf 
4. Santos YR, Oliveira VC, Guimarães EAA, Silva BS, Moraes JT, Cortez DN. Avaliação normativa das salas de vacina da região Oeste do estado de Minas Gerais, de outubro de 2015 a agosto de 2016. Vigil Sanit Debate [Internet]. 2017 [citado 2018 jul 13]; 5(3):44-52. Disponível em: https:// www.researchgate.net/publication/319438757_ Avaliacao_normativa_das_salas_de_vacina_da_ regiao_Oeste_do_estado_de_Minas_Gerais_de_ outubro_de_2015_a_agosto_de_2016

5. Champagne A, Hartz Z, Contandriopoulos AP, Denis JL. A análise de implantação. In: Brousselle A, Champagne F, Contandriopoulos AP, Hartz ZMA, organizadores. Avaliação em saúde: conceitos e métodos. Rio de Janeiro: Fiocruz; 2011. p.41-60.

6. Yin RK. Estudo de caso: planejamento e métodos. Porto Alegre: Bookman; 2015.

7. Moraes JT, Amaral CFS, Borges EL, Ribeiro MS, Guimarães EAA. Validation of an instrument for evaluating health care services to ostomized people. Rev Latino-am Enfermagem. 2016; 24:e2825. doi: http://dx.doi.org/10.1590/15188345.0748.2825

8. Guimarães EAA, Hartz ZMA, Loyola Filho AI, Meira AJ, Luz ZMP. Avaliação da implantação do Sistema de Informação sobre Nascidos Vivos em municípios de Minas Gerais, Brasil. Cad Saúde Pública. 2013; 29(10):2105-18. doi: http://dx.doi. org/10.1590/0102-311X00116312

9. Dias MSC, Paula MAB, Morita ABPS. Perfil Profissional de Enfermeiros Estomaterapeutas Egressos da Universidade de Taubaté. Braz J Enterestomal Ther [Internet]. 2014 [citado 2018 jul 13]; 12(3):14254. Disponível em: https://www.revistaestima. com.br/index.php/estima/article/view/92
10. Falkenberg MB, Mendes TPL, Moraes EP, Souza EM. Educação em saúde e educação na saúde: conceitos e implicações para a saúde coletiva. Ciênc Saúde Coletiva. 2014; 19(3):847-52. doi: http://dx.doi. org/10.1590/1413-81232014193.01572013

11. Grant MA, Corkle RM, Hornbrook MC, Wendel $\mathrm{SC}$, Krouse R. Development of a chronic care ostomy self-management program. J Cancer Educ. 2013; 28(1):70-8. doi: http://dx.doi. org/10.1007/s13187-012-0433-1

12. MirandaSM,LuzMHBA,SonobeHM,AndradeEMLR, Moura ECC. Caracterização Sociodemográfica e Clínica de Pessoas com Estomia em Teresina. Braz Enterestomal Ther. 2016; 14(1):29-35. doi: http:// dx.doi.org/10.5327/Z1806-314420160001000

13. Lenza NFB, Buetto LS, Vieira FS, Oliveira MS, Teles AAS, Sonobe HM. Necessidades do estomizado intestinal em seguimento oncológico: revisão integrativa. Rev Enferm UFPE on online [Internet]. 2015 [citado 2018 jul 13]; 9(Supl.6):871524. Disponível em: https://periodicos.ufpe. $\mathrm{br} / \mathrm{revistas} /$ revistaenfermagem/article/viewFile/10649/11668

14. Silva J, Sonobe HM, Buetto LS, Santos MG, Lima MS, Sasaki VDM. Teaching strategies for self-care of the intestinal stoma patients. Rev Rene. 2014; 15(1):166-73. doi: http://dx.doi. org/10.15253/2175-6783.2014000100021

15. Melo MDM. Integrative review of the defining characteristics in the nursing diagnosis: willingness to improved resilience in ostomized patients. Rev Min Enferm. 2015; 19(3):779-85. doi: http:// www.dx.doi.org/10.5935/1415-2762.20150059 